\title{
EVALUATION OF MIDTERM CLINICAL RESULTS IN PATIENTS UNDERGOING FULL ENDOSCOPIC TRANSFORAMINAL AND INTERLAMINAR DISCECTOMY
}

(D) Zafer Șen

\author{
University of Health Sciences Turkey, Konya Training and Research Hospital, Clinic of Orthopedics and Traumatology, Konya, Turkey
}

\begin{abstract}
Objective: This study aims to evaluate the midterm results and complications in patients undergoing discectomy via a lumbar interlaminar discectomy (ID) and transforaminal endoscopic discectomy (TFED) approaches.

Materials and Methods: Clinical and radiological data from 22 patients who underwent lumbar discectomy via transforaminal and interlaminar techniques between 2016 and 2020 were evaluated. In all the patients, the diagnosis was made by history, physical examination, plain radiography, and magnetic resonance imaging. Discectomy was performed using a minimally invasive method in patients that did not respond to medical treatment and were symptomatic.

Results: Thirteen male (59.1\%) and nine female (40.9\%) patients participated in the study. The average age of the patients was 49.4 (37.066.0). There was no significant difference between the groups in terms of gender and age $(p>0.05)$. All patients had radicular leg pain that was unresponsive to medical treatment. There was no loss of mobility and muscle strength in the legs of 4 patients in the postoperative period. The preoperative visual analog scale score was 8.36, whereas the scores in the $3^{\text {rd }}$ and $10^{\text {th }}$ months decreased significantly to 2.14 and 2.59 , respectively $(p<0.001)$. According to MacNab classification, only 1 patient in each group was classified as "fair"; $91.7 \%$ of the patients in ID group were classified as "excellent", whereas $90.0 \%$ of the patients in TFED group were classified as "good" $(p<0.001)$.

Conclusion: It was concluded that endoscopic discectomy techniques were found to be successful and reliable in selected patients. Moreover, the surgeon's experience directly affected the success of the surgery of discectomy.

Keywords: Lumbar disc herniation, transforaminal endoscopic discectomy, interlaminar discectomy
\end{abstract}

\section{INTRODUCTION}

In cases with symptomatic lumbar disc hernias, the goal is successful conservative treatment, but surgery is required when conservative possibilities are exhausted. As with most surgical approaches, endoscopic techniques are becoming more common in spinal surgery. After microdiscectomy has been used widely and became the gold standard in disc surgery since the 90s', endoscopic discectomy techniques have been used in certain centers ${ }^{(1,2)}$. Although traditional microdiscectomy methods are the gold standard, its damage to soft tissues should be considered (3). Conventional surgical approaches have good results ${ }^{(4-6)}$. However, in cases operated by conventional techniques, scarring occurs in the epidural space in $10 \%$ of cases, which could not be seen even by MR, and this becomes symptomatic ${ }^{(7)}$. These lesions generally tend to recur. Even if this is a pain syndrome, an endoscopic procedure is required to avoid these complications ${ }^{(7,8)}$. Minimally invasive techniques can eliminate tissue damage and related pain syndrome that may $\operatorname{occur}^{(9)}$. With the development of surgical techniques, transforaminal and interlaminar full endoscopic techniques are the most commonly used methods in percutaneous surgery. Techniques for these procedures were first described by Kambin and Gellman and developed by Yeung and Tsou ${ }^{(10)}$. First studies have achieved $88.2 \%$ of success ${ }^{(2,10,11)}$. In lumbar disc surgery, it must be reached the canal completely. Most authors accept limited restrictions in the lateral approach ${ }^{(3)}$. For example, in some cases with L5-S1 lumbar disc herniation, approaching transforaminal due to iliac crests restricts the surgeon ${ }^{(12)}$.

This study aims to evaluate the mid-phase results and complications of patients undergoing discectomy with a lumbar interlaminar discectomy (ID) and transforaminal endoscopic discectomy (TFED) approach in selected patients.

\section{MATERIALS AND METHODS}

In this study, clinical and radiological data of 22 cases who underwent a lumbar discectomy with transforaminal and interlaminar techniques between 2016 and 2020 were evaluated retrospectively. The study was conducted according

Address for Correspondence: Zafer Şen, University of Health Sciences Turkey, Konya Training and Research Hospital, Clinic of Orthopedics and Traumatology, Konya, Turkey

Phone: +90 5054628825 E-mail: zafersbukny@yahoo.com Received: 12.05.2021 Accepted: 31.01.2022

ORCID ID: orcid.org/0000-0001-9310-8245 
turkishspine

to the principles outlined in the Declaration of Helsinki. In all cases, the diagnosis was made by anamnesis, physical examination, direct radiography, and magnetic resonance imaging after receiving ethics approval (given by Necmettin Erbakan University, Meram Faculty of Medicine, NonPharmaceutical and Non-Medical Device Research Ethics Committee with 17/04/2020 date and 2020/2425 number). Discectomy was performed with the minimally invasive method in cases that did not respond to medical treatment and was symptomatic. Besides, it is stated that all cases were informed in detail on the treatments and an informed consent was obtained from each patient.

Our indications were defined by today's standards-based on radicular pain symptoms and existing neurological deficits ${ }^{(13,14)}$. Pain severity of the patients was evaluated with a visual analog scale (VAS) at pre-op, post-op 3 months, and 10 months periods. Ten-month satisfaction status was evaluated according to the MacNab classification given below:

Perfect: No pain, no working restrictions.

Good: Rarely back or leg pain, no hindrance to work.

Moderate: Intermittent pain, but cannot continue with the old job.

Bad: There is pain, need a second surgical procedure.

In addition to the demographic characteristics of all cases, changes in pain, operative time, and satisfaction level were evaluated.

\section{Surgical Techniques}

\section{a. TFED:}

The TFED approach is performed when the patient is in the prone position, on the translucent surgical table by biplane radiological imaging ${ }^{(15)}$. Then the midline and crista iliaca are marked with a marker pen (Figure 1).

By means of imaging, the dilator is placed in the target area after a tiny skin incision by means of a $1.5 \mathrm{~mm}$ atraumatic spinal guide. The atraumatic dilator with a diameter of $6.9 \mathrm{~mm}$ is transmitted through this guide. A guide wire is pulled and imaging is performed at this stage with scopy. Then, a $7.9 \mathrm{~mm}$ diameter surgical sheath is placed over the dilator (Figure 2). Image control is required at every stage of these processes. If the gap of the foramen does not allow the removal of the disc hernias or if stenosis exits, it can be needed to perform foraminoplasty with the help of a bone burr(16).

\section{b. ID:}

In an ID, the patient is performed in a prone position with biplane radiological imaging(3,16,17). The skin incision is made by approaching the medial side as much as possible from the craniocaudal center of the interlaminar window ${ }^{(18)}$.

The dilator with a diameter of $6.9 \mathrm{~mm}$ is sent from the medial side of the interlaminar window to the ligamentum filavum after incision. A curved surgical cannula with a diameter of $7.9 \mathrm{~mm}$ is sent afterward and controlled by imaging method (Figure 3).
Then, an incision with 3-6 mm diameter is made over the ligamentum flavum, the region where the incision is made is expanded and penetrated the canal by means of the imaging device (Figure 4).

The adipose tissue is dissected in a controlled manner and partially resected. With the help of the control probe, the lesion is checked (Figure 5).

The root is eliminated with the help of a surgical cannula with a curved tip of $7.9 \mathrm{~mm}$ in diameter. If the interlaminar gap does not allow to penetrate the canal at these stages, or if there exists stenosis, bone resection may be required (Figure 6) ${ }^{(18)}$.

\section{Surgery Follow-up}

Patients are mobilized after 3 hours for general anesthesia and 6 hours for spinal anesthesia in the postoperative period. In the

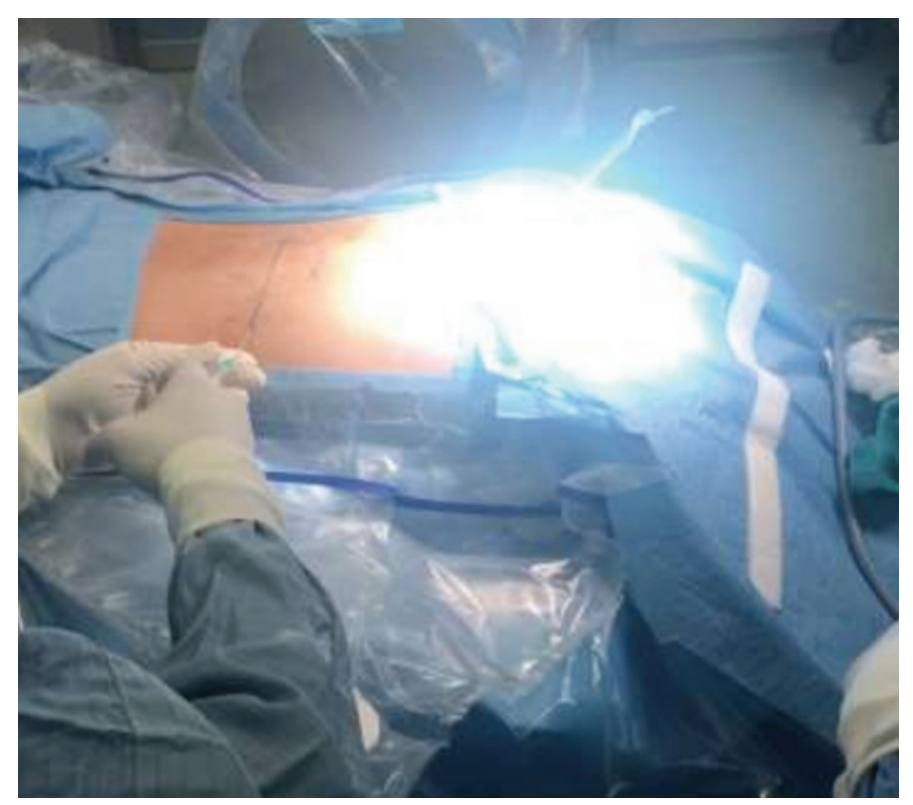

Figure 1. Penetrating by means of marking and imaging

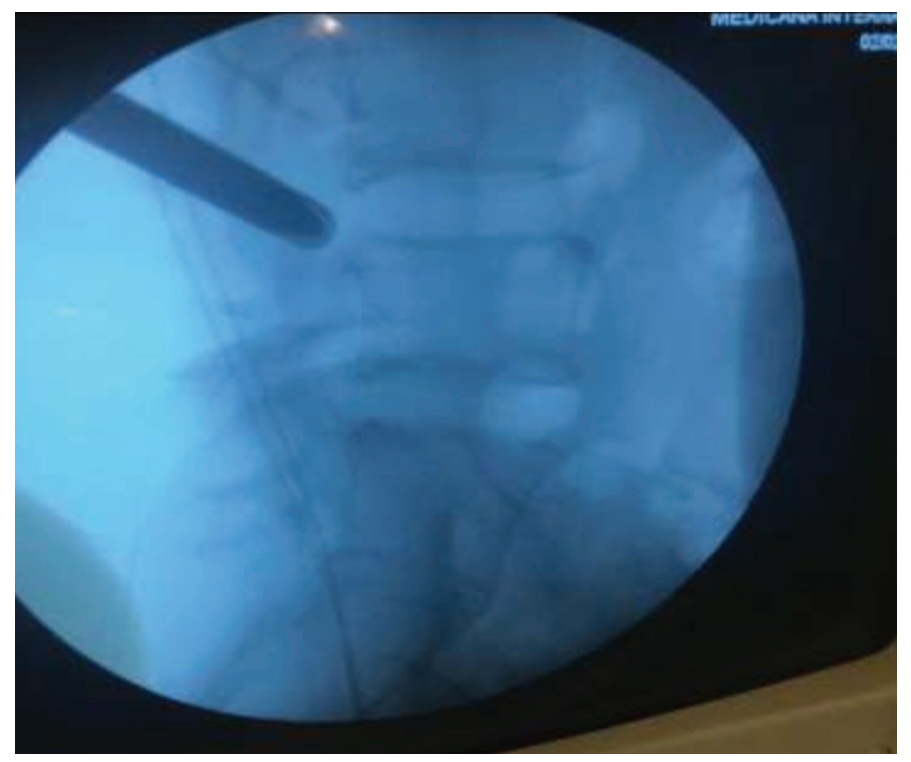

Figure 2. Image control with dilator and surgical sheath 


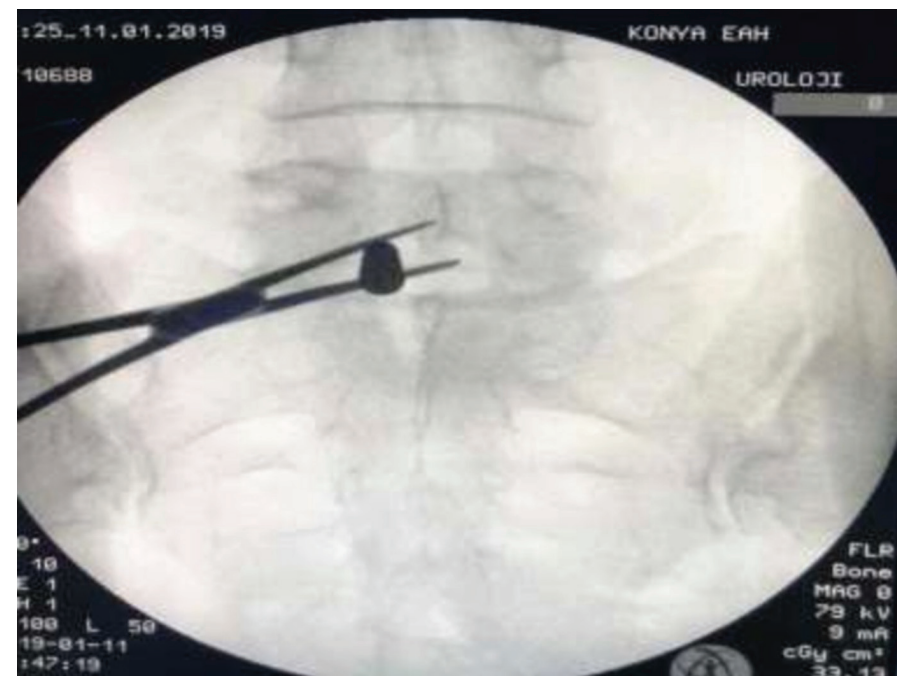

Figure 3. ID access control

ID: Interlaminar discectomy

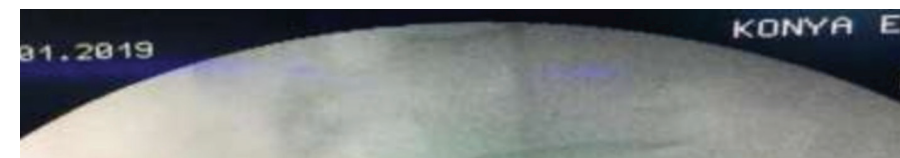

Figure 4. ID lateral control

ID: Interlaminar discectomy

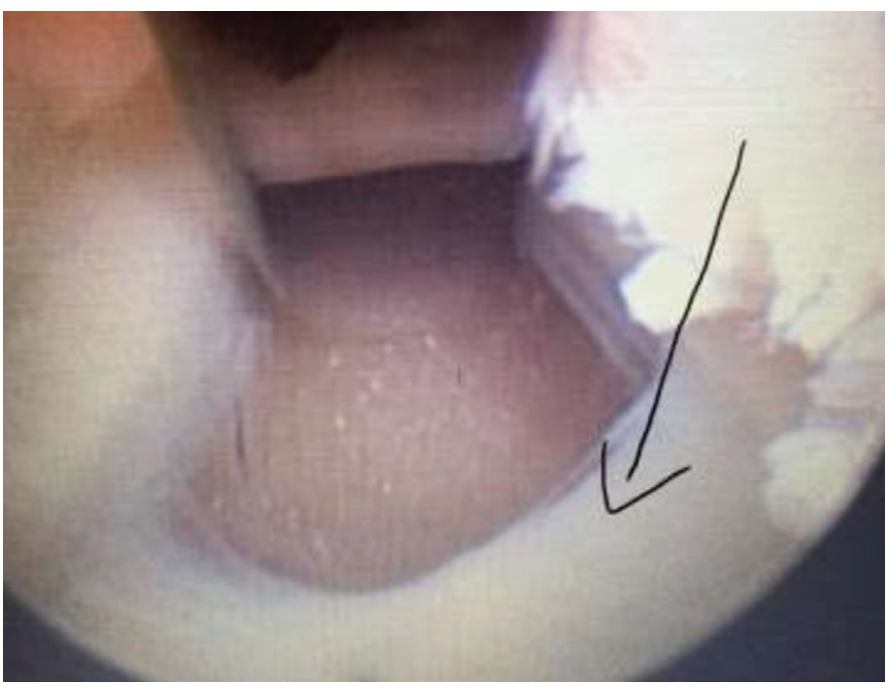

Figure 5. Ligamentum flavum first 3 days, short walks can be suggested in the house allowing one to sit at short intervals. All patients are allowed to go to their occupation after one week.

\section{RESULTS}

This study was conducted with 13 male (59.1\%) and 9 female (40.9\%) patients. Of the 22 cases included in the study, $18.18 \%$ $(n=4)$ of the cases was median, $36.36 \%(n=8)$ paramedian, $27.27 \%(n=6)$ foraminal and $18.18 \%(n=4)$ distal lumbar disc hernias (LDHs). The median and paramedian cases $(n=12)$ were administered ID, and the patients with LDH $(n=10)$ located in the foraminal and distant lateral position $(n=10)$ were administered TFED. There were 10 cases (45.5\%) L5-S1, 7 cases (31.8\%) L4L5, and 5 cases (22.7\%) L3-L4 lumbar disc herniation. Fourteen cases $(63.6 \%)$ were performed by anesthesiologists with spinal anesthesia and the rest of the cases (36.4\%) were operated under general anesthesia.

The average age of the cases was $49.4^{(13,19)}$. There was no significant difference between the surgical methods as gender and age $(p>0.05)$. All patients had radicular leg pain that was unresponsive to medical treatment. There was a force in four cases. The preoperative VAS score was 8.36 whereas the scores at $3^{\text {rd }}$ and $10^{\text {th }}$ months decreased significantly to 2.14 and 2.59 respectively $(p<0.001)$.

The LDH levels did not differ significantly between the techniques $(p=0.702)$. Only the L4-L5 level was lower in the TFED group. The LDH location of the cases was significantly different between the groups $(p<0.001)$, such that all patients in the ID technique were median (33.3\%) and paramedian (66.7\%), and the others were foraminal (60.0\%) and distal lateral (40.0\%). No intra-op complications improved in any case, and all of them were discharged on post-op $1^{\text {st }}$ day. It was observed no neurological deficits in the post-op period. The operation times were similar between the techniques $(p=0.821)$, and the average time was 34.95 mins $^{(15,17)}$.

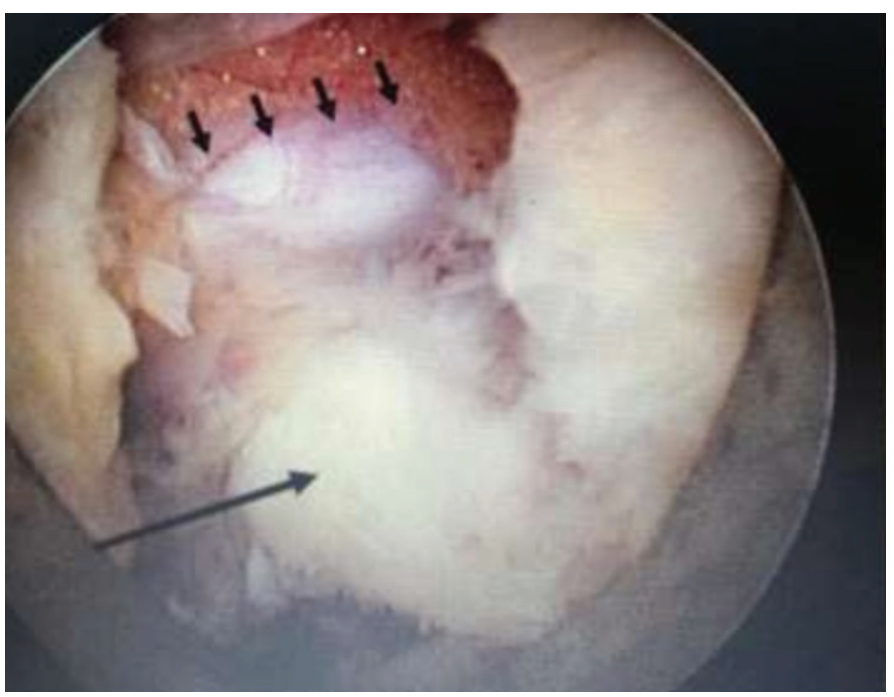

Figure 6. Disc herniation and root compression 
The early satisfaction rate in the cases was determined as $81 \%$. At the $3^{\text {rd }}$ month follow-up, pregabalin $50 \mathrm{mg} /$ day and paracetamol $1000 \mathrm{mg} /$ day were medicated in four patients with pain reflected on the hip. Patients' complaints decreased significantly, and the satisfaction rate has reached $100 \%(n=22)$ after the follow-up of the $3^{\text {rd }}$ month. According to MacNab classification, only one patient in each group was in fair class, and $91.7 \%$ of the patients in the ID group was in "excellent" whereas $90.0 \%$ of the patients in the TFED group was in "good" class $(p<0.001)$ (Table 1$)$.

\section{DISCUSSION}

The goal of the treatment of LDH surgery is to provide an adequate decompression with minimized surgical trauma. In this study, we showed that an adequate decompression was achieved with complete endoscopic transforaminal and ID, as an alternative way to microdiscectomy, and compatible with the literature.

Endoscopic transforaminal and ID yields similar results to other microscopy-supported conventional surgical techniques $(4-6,20)$. The success of an adequate decompression technique similar to the endoscopic discectomy method and other conventional procedures has also been demonstrated in a prospective randomized study using specific inclusion criteria(6).

Table 1. Characteristics of the patients with lumbar disc hernia

\begin{tabular}{|c|c|c|c|c|c|}
\hline \multicolumn{2}{|l|}{ LD Surgery type } & Interlaminar $(n=12)$ & Transforaminal $(n=10)$ & Total & \multirow[b]{2}{*}{$p$} \\
\hline & & \multicolumn{3}{|l|}{ Mean \pm SD } & \\
\hline Age & Year & $48.75 \pm 7.66$ & $50.30 \pm 10.56$ & $49.45 \pm 8.90$ & 0.722 \\
\hline Operation time & Minute & $36.08 \pm 11.01$ & $33.60 \pm 8.87$ & $34.95 \pm 9.94$ & 0.821 \\
\hline VAS Pre-op ${ }^{\dagger}$ & Score & $8.33 \pm 0.88$ & $8.40 \pm 0.51$ & $8.36 \pm 0.72$ & 0.872 \\
\hline VAS $3^{\text {rd }}$ month $^{\dagger}$ & Score & $2.17 \pm 0.57$ & $2.10 \pm 0.73$ & $2.14 \pm 0.64$ & 0.875 \\
\hline \multirow[t]{2}{*}{ VAS $10^{\text {th }}$ month } & Score & $2.50 \pm 0.67$ & $2.70 \pm 0.48$ & $2.59 \pm 0.59$ & 0.381 \\
\hline & & n (\%) & n (\%) & $n(\%)$ & \\
\hline \multirow{2}{*}{ Gender } & Male & $8(66.7)$ & $5(50.0)$ & $13(59.1)$ & \multirow{2}{*}{0.439} \\
\hline & Female & $4(33.3)$ & $5(50.0)$ & $9(40.9)$ & \\
\hline \multirow{4}{*}{ LDH location } & Median & $4(33.3)$ & 0 & $4(18.2)$ & \multirow{4}{*}{$<0.001^{*}$} \\
\hline & Paramedian & $8(66.7)$ & 0 & $8(36.4)$ & \\
\hline & Foraminal & 0 & $6(60.0)$ & $6(27.3)$ & \\
\hline & Distant lateral & 0 & $4(40.0)$ & $4(18.2)$ & \\
\hline \multirow{3}{*}{ LDH level } & L5-s1 & $4(33.3)$ & $6(60.0)$ & $10(45.5)$ & \multirow{3}{*}{0.702} \\
\hline & L4-I5 & $6(50.0)$ & $1(10.0)$ & $7(31.8)$ & \\
\hline & L3-L4 & $2(16.7)$ & $3(30.0)$ & $5(22.7)$ & \\
\hline \multirow{2}{*}{ Anesthesia type } & General & $4(33.3)$ & $4(40.0)$ & $8(36.4)$ & \multirow{2}{*}{0.752} \\
\hline & Spinal & $8(66.7)$ & $6(60.0)$ & $14(63.6)$ & \\
\hline MacNab & Fair & $1(8.3)$ & $1(10.0)$ & $2(9.1)$ & $0.001^{*}$ \\
\hline \multirow{2}{*}{ Classification } & Good & 0 & $9(90.0)$ & $9(40.9)$ & \\
\hline & Excellent & 11 (91.7) & 0 & $11(50.0)$ & \\
\hline
\end{tabular}

*: Significant at $p<0.05$ level according to exact chi-square test

†: Significant at $p<0.001$ level according to Friedman's Two-Way ANOVA post-hoc test for VAS scores

LDH: Lumbar disc hernia, VAS: Visual analogue scale, SD: Standard deviation
It has been stated that when resection of spinal canal structures is prevented, minimally traumatic disc resection can decrease the operative segmental instability ${ }^{(7,13,14,21)}$. Operation time, tissue trauma, and complications decrease compared to the conventional procedures ${ }^{(15,22,23)}$. It was reported that the patient retrieves his peri-operative activity level and increases the life comfort by minimally invasive methods ${ }^{(24)}$. It has been observed that the rehabilitation precautions related to the operation are not necessary. It was reported that the pain accompanied with ID or TFED does not have surgical origination ${ }^{(21,25,26)}$ and comorbid diseases do not affect to increase in morbidity ${ }^{(15)}$. Adhesions found intraoperatively can also be seen in cases that have not been previously operated on and often undiagnosed by imaging methods. Adhesions may occur as a result of degenerative and inflammatory processes ${ }^{(8,27)}$. Although general and spinal anesthesia was used in this study, it is also possible to use local anesthesia ${ }^{(22,28-30)}$.

In this study, it was observed that ID and TFED were effective in the short and medium-term in selected patients. As in all discectomy methods, post-operative success in endoscopic methods depends on the well-selected patient group and the surgeon's experience. In discectomy surgery performed with conventional surgical techniques, stripping of the paraspinal muscles, lamina, facet joint, and partial resection of ligamentum 
flavum can be applied(11). Although the conventional surgical techniques have good results, scar tissue occurring in the spinal canal in the post-operative period can be developed at $10 \%$ of the patients, and therefore a revision is needed ${ }^{(31)}$. On the other hand, revision surgery is complicated, and it is also difficult in terms of surgical procedures. In some studies, it has been stated that resection of spinal canal structures leads to spinal instability, and the incidence of spondylolisthesis was reported as $2-10 \%$. Besides, the incidence of post-op progressive progression increases in the patients with preoperative spondylolisthesis. After microdiscectomy operation, nerve injuries, cerebrospinal fluid fistula, meningitis, and wound problems may occur. Studies report $4 \%$ of dura injuries and this rate is reported as $17 \%$ in subsequent surgeries ${ }^{(11,31)}$.

Endoscopic discectomy methods are less invasive than conventional methods. The risk of scar development is lower in intra-canal structures ${ }^{(32,33)}$. Yeung and Tsou $^{(10)}$ reported the risk of dura injury to endoscopic methods as $0.3 \%$ in their studies $^{(11)}$. In our study, none of our patients had dura injuries, and no neurological deficits developed in the post-op term. With endoscopic methods, patients can be discharged on the first day of post-op and can be rehabilitated quickly with a short operation time, since the anatomical structures are traumatized during the procedures, the post-op pain is low and the risk of instability is reduced. Early mobilization, early work start, low pain, and early discharge are the main advantages of endoscopic methods(2,11,29,32,33). Endoscopic discectomy revision operations are much easier compared to classical surgery. The recurrence rate after endoscopic discectomy has been reported as $5 \%$ in the studies of Yeung and Tsou ${ }^{(10)}$ and Hoogland et al. ${ }^{(32,33)}$. The standard indication in endoscopic discectomies is disc pathologies that cause discogenic lower-extremity pain(11). The presence of advanced paresis, cauda syndrome, some neurological symptoms, and segmental instability are contraindications for endoscopic surgery ${ }^{(11,19,31)}$.

Infection, dysesthesia, dura, and vascular injuries are among the post-op complications of endoscopic discectomy, and the complication rate is between $2.7-3.5 \%$. In conventional surgery, this rate is given as $6 \%^{(1)}$. No complication was observed in any of our patients. It is emphasized that the endoscopic discectomy gives similar results to microdiscectomy. In an article published by Tzaan ${ }^{(11)}, 134$ patients who underwent TFED were evaluated according to the modified MacNab criteria. $89 \%$ of patients were reported "excellent" or "good" results after surgery $(28 \%$ excellent $(n=38), 61 \%$ good $(n=82)$. Only $7 \%$ of the patients were in "fair" and $4 \%$ of them in the "poor" class. Those 6 patients (4\%) with poor results were re-operated. Temporary dysesthesia occurred below the leg in 8 patients (5.9\%) after the operation, which improved within 3 months ${ }^{(1)}$.

In our study, $90.9 \%$ of the cases had good or excellent results and $9.1 \%$ of them had fair results according to the modified MacNab classification. Two patients had leg pain in the early period, and their complaints were relieved with paracetamol $1000 \mathrm{mg} /$ day and pregabalin $50 \mathrm{mg} /$ day.
In a study by Hoogland et al.(32), 142 patients underwent TFED ${ }^{(1)}$. Patients were evaluated 1 year later according to the VAS and MacNab criteria. The pre-op VAS value of leg pain was 8.2 while the post-op VAS value was 2.6 at the end of one year. According to the MacNab classification, $50.8 \%$ of excellent and $33.8 \%$ of good results were obtained at the end of two years. While $14.4 \%$ of the patients had moderate satisfaction, $0.9 \%$ (1 patient) was reported having a poor result.

\section{CONCLUSION}

It can be concluded that the endoscopic discectomy methods were found to be significant and reliable in selected cases. However, the surgeon's experience directly affects the success of the technical change of the disc location.

\section{Ethics}

Ethics Committee Approval: Ethic committee approval was obtained from Necmettin Erbakan University, Meram Faculty of Medicine, Non-Pharmaceutical and Non-Medical Device Research Ethics Committee with 17/04/2020 date and 2020/2425 number.

Informed Consent: Informed consent was obtained from each patient.

Peer-review: Externally peer-reviewed.

Financial Disclosure: The author declared that this study received no financial support.

\section{REFERENCES}

1. Ilaslan H, Aslan A, Koç ÖN, Dalkiliç T, Naderi S. Transforaminal endoscopic discectomy in lumbar disc herniations. J Neurol Sci. 2010;27:104-10.

2. Mayer HM, Brock M. Percutaneous endoscopic lumbar discectomy. Neurosurgery. 1993;16:115-20.

3. Ruetten S, Komp M, Godolias G. A new full-endoscopic technique for the interlaminar operation of lumbar disc herniations using 6-mm endoscopes: Prospective 2-year results of 331 patients. Minimally Invasive Neurosurgery. 2006;49:80-7.

4. Ebeling U, Reichenberg W, Reulen HJ. Results of microsurgical lumbar discectomy - Review on 485 patients. Acta Neurochir (Wien). 1986;81:45-52.

5. Ferrer E, García-Bach M, López L, Isamat F. Lumbar microdiscectomy: analysis of 100 consecutive cases. Its pitfalls and final results. Acta Neurochirurgica 1988; Suppl 6-11.

6. Hermantin FU, Peters T, Quartararo L, Kambin P. A prospective, randomized study comparing the results of open discectomy with those of video-assisted arthroscopic microdiscectomy. J Bone Joint Surg. 1999;81:958-65.

7. Schoeggl A, Maier H, Saringer W, Reddy M, Matula C. Outcome after chronic sciatica as the only reason for lumbar microdiscectomy. I Spinal Disord Tech. 2002;15:415-9.

8. Kraemer J. Intervertebral Disk Diseases (2nd Ed). Thieme Publishers, Stuttgart, Germany, 1990, pp.56-77.

9. Weber BR, Grob D, Dvorák J, Müntener M. Posterior surgical approach to the lumbar spine and its effect on the multifidus muscle. Spine. 1997;22:1765-72

10. Yeung AT, Tsou PM. Posterolateral endoscopic excision for lumbar disc herniation: Surgical technique, outcome, and complications in 307 consecutive cases. Spine. 2002;27:722-31. 
11. Tzaan WC. Transforaminal percutaneous endoscopic lumbar discectomy. Chang Gung Med J. 2007;30:226.

12. Yeung AT, Yeung CA, Zheng Y. Posterolateral Selective Endoscopic Discectomy the YESS Technique. Minimally Invasive Procedures in Spine Surgery 2013;121-32.

13. Mochida J, Toh E, Nomura T, Nishimura K. The risks and benefits of percutaneous nucleotomy for lumbar disc herniation. J Bone Joint Surg Br. 2001;83:501-5.

14. Zander T, Rohlmann A, Klöckner C, Bergmann G. Influence of graded facetectomy and laminectomy on spinal biomechanics. Eur Spine J. 2003; 12:427-34.

15. Stolke D, Sollmann WP, Seifert V. Intra- and postoperative complications in lumbar disc surgery. Spine. 1989;14:56-9.

16. Ruetten $\mathrm{S}$. The full-endoscopic interlaminar approach for lumbar disc herniations. J Minim Invasive Spine Surg Tech. 2006;346-55.

17. Ruetten S, Komp M, Godolias G. An extreme lateral access for the surgery of lumbar disc herniations inside the spinal canal using the full-endoscopic uniportal transforaminal approach-technique and prospective results of 463 patients. Spine. 2005;30:2570-78.

18. Ruetten S, Komp M, Merk H, Godolias G. Use of newly developed instruments and endoscopes: Full-endoscopic resection of lumbar disc herniations via the interlaminar and lateral transforaminal approach. Journal of Neurosurgery Spine. 2007;6:521-30.

19. Schubert M, Hoogland T. Endoscopic transforaminal nucleotomy with foraminoplasty for lumbar disk herniation. Operative Orthopadie und Traumatologie. 2005;17:641-61.

20. Andrews DW, Lavyne MH. Retrospective analysis of microsurgical and standard lumbar discectomy. Spine. 1990;15:329-35.

21. Ross JS, Robertson JT, Frederickson RCA, Petrie JL, Obuchowski N, Modic MT, et al. Association between Peridural Scar and Recurrent Radicular Pain after Lumbar Discectomy: Magnetic Resonance Evaluation. Neurosurgery. 1996;38:855-63.

22. Choi G, Lee SH, Raiturker PP, Lee S, Chae YS. Percutaneous endoscopic interlaminar discectomy for intracanalicular disc herniations at L5-S1 using a rigid working channel endoscope. Neurosurgery. 2006;58:59-68.

23. Mayer HM. The microsurgical interlaminar, paramedian approach. (In: Minimally Invasive Spine Surgery, Mayer HM (Ed)) (2nd Ed), Springer-Verlag, Berlin, Germany, 2000, pp.71-79.
24. Donceel $\mathrm{P}, \mathrm{Du}$ Bois $\mathrm{M}$. Fitness for work after surgery for lumbar disc herniation: A retrospective study. Eur Spine J. 1998;7:29-35.

25. Balderston RA, Gilyard GG, Jones AA, Wiesel SW, Spengler DM, Bigos SJ, et al. The treatment of lumbar disc herniation: Simple fragment excision versus disc space curettage. J Spinal Disord. 1991;4:22-5.

26. Mochida J, Nishimura K, Nomura T, Toh E, Chiba M. The importance of preserving disc structure in surgical approaches to lumbar disc herniation. Spine. 1996;21:1556-63.

27. Ruetten S, Meyer O, Godolias G. Epiduroscopic diagnosis and treatment of epidural adhesions in chronic back pain syndrome of patients with previous surgical treatment: First results of 31 interventions. Zeitschrift fur Orthopadie und ihre Grenzgebiete. 2002; 140:1171-75.

28. Chiu JC, Clifford T, Princenthal R, Shaw S. Junctional disc herniation syndrome in post spinal fusion treated with endoscopic spine surgery. Surg Technol Int. 2005;14:305-15.

29. Tsou PM, Yeung CA, Yeung AT. Posterolateral transforaminal selective endoscopic discectomy and thermal annuloplasty for chronic lumbar discogenic pain: A minimal access visualized intradiscal surgical procedure. Spine. 2004;4:564-73.

30. Yeung AT, Yeung CA. Advances in endoscopic disc and spine surgery: foraminal approach. Surg Technol Int. 2003;11:255-63.

31. Ruetten S, Komp M, Merk H, Godolias G. Full-endoscopic interlaminar and transforaminal lumbar discectomy versus conventional microsurgical technique: A prospective, randomized, controlled study. Spine. 2008;33:931-9.

32. Hoogland T, Schubert M, Miklitz B, Ramirez A. Transforaminal posterolateral endoscopic discectomy with or without the combination of a low-dose chymopapain: A prospective randomized study in 280 consecutive cases. Spine. 2006;31:E890-7.

33. Hoogland T, Van Den Brekel-Dijkstra K, Schubert M, Miklitz B. Endoscopic transforaminal discectomy for recurrent lumbar disc herniation: A prospective, cohort evaluation of 262 consecutive cases. Spine. 2008;33:973-8. 